Andrzej Kraslawski and Ilkka Turunen (Editors) Proceedings of the $23^{\text {rd }}$ European Symposium on Computer Aided Process Engineering - ESCAPE 23 June 9-12, 2013, Lappeenranta, Finland,

(C) 2013 Elsevier B.V. All rights reserved.

\title{
Multi-objective optimization of SNG production through hydrothermal gasification from microalgae
}

\author{
Alberto Mian $^{\mathrm{a}}$, Adriano V. Ensinas ${ }^{\mathrm{a}}$, François Marechal ${ }^{\mathrm{a}}$ \\ ${ }^{a}$ Industrial Energy Systems Laboratory (LENI), Ecole Polytechnique Fédérale de \\ Lausanne, CH-1015 Lausanne, Switzerland, adriano.ensinas@epfl.ch
}

\begin{abstract}
Microalgae cultivation for biofuel conversion is widely treated in literature as it could allow reducing fossil fuel consumptions. One of the challenges of this technology is related to the high power and cost requirements for the harvesting and dewatering steps. The influence of dewatering process can be substantially reduced when considering hydrothermal gasification (HTG). This technology, which have already been demonstrated and tested, allows treating feedstock with more than $80 \%$ moisture content and can lead to high SNG conversion efficiencies. The object of this paper is to show the combination of microalgae growing and processing coupled with the HTG and syngas purification for SNG grid quality production. The productivity potential for this given technology is evaluated considering global solar radiation data available and the cultivation technology, which can be characterized by photosynthesis conversion efficiency. Systematic system design methodology followed by multi-objective optimization technique using evolutionary algorithms are carried out to provide a set of candidate solutions considering different configurations and conflictive objectives such as efficiency, cost and environmental impact.
\end{abstract}

Keywords: microalgae, hydrothermal gasification, process design, thermoeconomic optimization, synthetic natural gas.

\section{Introduction}

The motivation to develop biofuels has been the exploitation of photosynthesis for capturing atmospheric $\mathrm{CO}_{2}$ and producing renewable fuels. They can provide a means to stabilize $\mathrm{CO}_{2}$ levels in the atmosphere replacing fossil based fuels, but its environmental benefits as energy source contrast with the impact on global food supply security. The expansion of agricultural biofuel production in arable land in many countries has raised the public awareness of land competition for producing either food or biofuels.

In order to solve the problems which are related to bioenergy, new process based on the conversion of microalgae as feedstock have been studied in the last decades (Brennan and Owende, 2010).

The efficient energy conversion of wet biomass like microalgae is challenging since it is available at solid concentrations bellow $5 \mathrm{~g} / \mathrm{L}$. Considering this fact, catalytic hydrothermal gasification is a promising emerging technology for the production of Synthetic Natural Gas (SNG) since it does not suffer from an incomplete conversion like biomethanation and may efficiently convert diluted feedstocks like sewage sludge, manure, food processing residues (Gassner et al. 2011). Relatively low energy consuming dewatering technologies are required to increase the biomass solid content 
up to $10-20 \mathrm{wt} \%$, which reduces significantly the total energy demand when compared with processes requiring dry biomass as feedstock.

This paper describes the SNG production through the conversion of microalgae biomass in catalytic hydrothermal gasification process with supercritical water. Systematic system design methodology followed by multi-objective optimization technique using evolutionary algorithms provides a set of candidate solutions to the design problem considering different objectives as such total cost and SNG production.

\section{Process modeling strategy}

Following a systematic process design methodology, all the steps from the microalgae biomass production to the final product purification are considered. The complete flowsheet model is developed in Besim Vali software with accurate thermodynamic property models for the hydrothermal conversion previously developed by Gassner et al. (2011). The Figure 1 shows the basic steps and flows considered in the analysis.

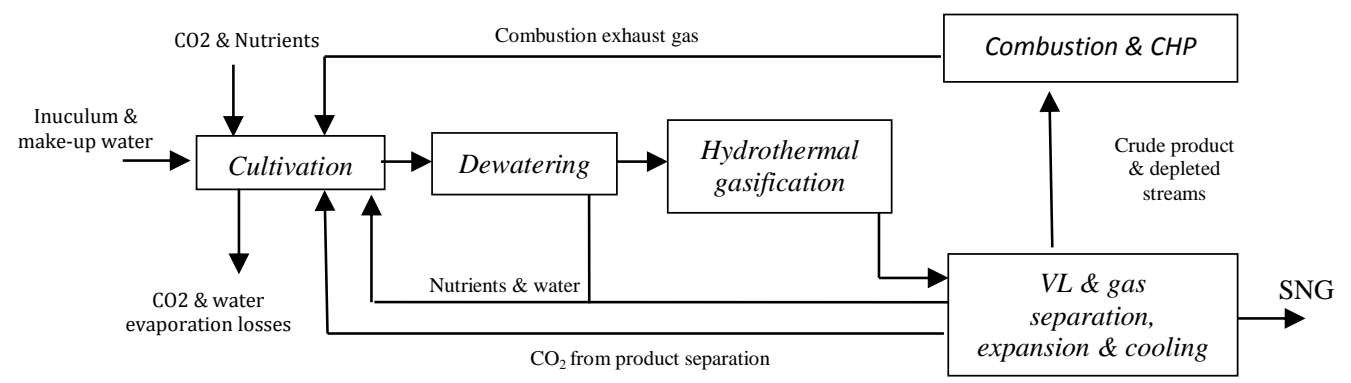

Figure 1. Conceptual microalgae-to-SNG process configuration

\subsection{Microalgae cultivation and dewatering}

According to Benemann (2008), about $98 \%$ of commercial algae biomass production is currently with open ponds, even for high value nutritional products, which sell for prices over a thousand-fold higher that allowable for biofuels. Therefore, the feasibility of microalgae production for biofuels is intrinsically linked with biomass production cost reduction and high production rates.

Efficient photobioreactor cultivation systems have been highlighted as promising alternatives for production of microalgae in large scale, but it must be noted that almost no information is available about detailed designs, operations, yields, and other important aspects of these systems which can limit correct estimation of biofuels production costs from microalgae (Benemann, 2008).

Most of the current activities to produce biofuels from microalgae are actually based on open ponds because of their low costs and low demands on auxiliary energy. As a preliminary study about the potential of the SNG production using microalgae this system is chosen as reference for the analysis presented in this paper.

Thus, the cultivation system comprises raceways-type open ponds with $0.3 \mathrm{~m}$ of depth and water circulation system with electric-driven paddle wheels. The detailed design of the series of ponds and auxiliaries are obtained from Weissman and Goebel (1987). The 
Multi-objective optimization of SNG production through hydrothermal gasification from microalgae

system includes lined ponds made of concrete with unit dimension between 2 and 10 ha each and $\mathrm{CO}_{2}$ rich-air bubbling system which can lead to microalgae concentration of $0.5 \mathrm{~g} / \mathrm{L}$ with a retention time of 4 days.

One dewatering system is carried out in this paper, including a primary step of settling and thickening tanks that can increase the concentration of the biomass up to $2.5 \%$ of solids and a secondary step comprised by disk-stack centrifuges that can provide the final concentration of solids required by the hydrothermal gasification system.

\subsubsection{Biomass productivity}

The productivity of the cultivation process is defined based on the photosynthetic conversion efficiency (PCE), that is independent of the radiation level, but on the photobioreactor type (Norsker et al. 2011) and can be defined as:

$P C E=\frac{E b}{I}=\frac{P b \times L H V_{b}}{I}$

where $E b$ is the biomass energy production per surface of the cultivation system per day $\left[\mathrm{kJ} \mathrm{m}^{-2} \mathrm{~d}^{-1}\right]$ and $I$ is the total daily solar radiation incidence in the same surface $\left[\mathrm{kJ} \mathrm{m}^{-2}\right.$ $\mathrm{d}^{-1}$ ]. $E b$ can also be obtained by the multiplication of the $P b$ that is the specific daily biomass productivity of the biomass in the cultivation system $\left[\mathrm{kg} \mathrm{m}^{-2} \mathrm{~d}^{-1}\right]$ and the $L H V b$, lower heating value of the dry ash free biomass $\left[\mathrm{kJ} \mathrm{kg}^{-1}\right]$.

The energy from incident sunlight cannot be converted entirely into biomass in microalgae cultivation systems because of several physiological properties that reduce the efficiency of photosynthesis (Williams and Laurens, 2010, Park et al., 2011, Schlagermann et al., 2012).

According to Schlagermann et al. (2012), considering all the energy losses described above, the theoretical maximum PCE of $12.4 \%$ is achieved. Carvalho et al. (2006) affirms that microalgae conserve a maximum of $9-10 \%$ of the solar radiation but microalgal outdoor production system so-far rarely exceed $6 \%$.

Actually, the real PCE in outdoor algal cultures decreases to a value between $1.5 \%$ and $5 \%$ depending on the cultivation system (raceways pond or closed systems), mixing and weather conditions. Further losses of energy are the reflection of light on water bodies at the reactor surface $(\sim 10 \%)$, photosaturation and photoinhibition $(\sim 40 \%)$, and respiration ( 20\%) (Tridici, 2010). Many authors show that usual crop biomass PCE does not exceed $1 \%$ in temperate regions. (Boyer, 1982; Posten and Schaub, 2009).

In this paper the PCE for the raceway system is assumed as $1.5 \%$ according to the study of Norsker et al. (2011). Therefore, with a fixed value for the PCE, the productivity depends of the solar radiation incidence in the pond localization. Available data from a tropical region is chosen as case study. Average annual radiation was used as input for the model, since it is not in the scope of this preliminary study the evaluation of the productivity around the year.

\subsubsection{Biomass characterization and $\mathrm{CO} 2$ requirement}

In this paper the minimum $\mathrm{CO}_{2}$ requirement for the biomass cultivation is calculated by the carbon balance in the pond, considering the $\mathrm{CO}_{2}$ injected as the only source of carbon for the biomass growth. 
The fraction of each principal biochemical classes of molecules are considered as $5 \%$ of Nucleic Acids, $15 \%$ of Lipids and the Protein:Carbohydrate ration constant at 3:2. Thus, the weight base elemental composition of the dry ash free microalgae biomass was calculated as $51 \% \mathrm{C}, 6.8 \% \mathrm{H}, 31.6 \% \mathrm{O}, 9.5 \% \mathrm{~N}, 1.1 \% \mathrm{~S}$ (Williams and Laurens, 2010). The low heating value of the biomass $(L H V b)$ is estimated as $22.3 \mathrm{MJ} \mathrm{kg}^{-1}$ based on its elemental composition following the Boie's correlation (Annamalai et al. 1987). When microalgae are cultivated in open ponds using as carbon source the $\mathrm{CO}_{2}$ taken from the atmosphere, the PCE is around $0.5 \%$. Improvements can be obtained with paddlewheels to move the water in annular channels called raceways, allowing a better mixing of the cells for gas transfer and exposure to the bright surface for photosynthesis.

Raceways $\mathrm{CO}_{2}$ enriched-air bubbling system commonly suffer from residence times due to the shallow depths and poor mass transfer rates, resulting in losses of $\mathrm{CO}_{2}$ to the atmosphere through the surface, increasing the operating costs (Carvalho et al., 2006). Improvements can be obtained by different approaches such as in-pond $\mathrm{CO}_{2}$ transfer sumps (Park et al., 2011; Campbell et al.,2011) and $\mathrm{CO}_{2}$ transfer stations adjacent to the raceway ponds (Putt et al., 2011).

Efficiency of $\mathrm{CO}_{2}$ utilization is between 2 and $35 \%$ depending of the $\mathrm{CO} 2$-air ratio and the technology of the reactor (Ketheesan and Nirmalakhandan, 2012). In this paper the $\mathrm{CO}_{2}$ requirement for the carbon fixation in the microalgae growth is carried out considering the gas injection system in the pond with carbon dioxide-to-air ratio of $5 \%$ and efficiency of utilization of $36 \%$ (Putt et al., 2011).

\subsection{Hydrothermal Gasification and SNG separation}

The hydrothermal gasification of biomass in supercritical water is a promising process alternative to produce SNG. The resulting products are methane as a clean fuel and concentrated $\mathrm{CO}_{2}$ for recuperation in the bioreactor or for efficient sequestration.

The advantage using hydrothermal gasification is the availability of output streams such salts, clean water and carbon dioxide. It is thus possible to study the influence of recirculating materials between the gasification process and the algae cultivation pond which leads to decreasing of operation costs and environmental impact of SNG produced.

The product separation step is modelled including the water absorption tower column and membranes. Due to supercritical conditions the syngas expansion to grid conditions potentially allows mechanical energy recovery. Strategies for a integrated separation of the crude product, heat supply and energy recovery are carried out in the general superstructure described in Gassner et al. (2011).

\section{Optimization procedure}

The multi-objective optimization procedure is performed following a methodology successfully applied to study biofuels production pathways, including the SNG, liquid fuels and $\mathrm{H}_{2}$ and power plants applications using different types of feedstocks and comparing different $\mathrm{CO}_{2}$ capture options (Gerber et al. 2011, Gassner et al. 2011).

This systematic approach for the thermo-environomic modeling, analysis and optimization combines flowsheeting, energy integration techniques and multi-objective optimization strategies. 
Multi-objective optimization of SNG production through hydrothermal gasification from microalgae

In the present paper the optimization of the system design in carried out considering as objective functions the minimization of the total cost (operation and investiment) and the maximization of the SNG produced. The decision variables included some parameters with the range presented below and integer variables to select or not the options of syngas and liquid expansion for power recovery.

- Pressure of the gasifier: 220-300bar

- Salt separation maximum temperature: $703.15-823.15 \mathrm{~K}$

- $\mathrm{CH}_{4}$ content in the crude SNG produced: 0.85-0.94

\section{Results and Discussion}

The results of multi-objective optimization for a constant dry ash free microalgae biomass input of $20 \mathrm{MW}$ in the hydrothermal gasification plant are show in the Figure 2. The set of optimal solutions indicate a slightly increase of the total cost with the increase of the SNG output. This is due mainly to the increase of pressure of the gasification system and temperature of salts separation. The total specific cost of the SNG produced is between 44 and $53 \mathrm{US} \$ / \mathrm{MWh}_{\mathrm{SNG}}$, while the $\mathrm{SNG}$ output has values between 10.1 and $12.1 \mathrm{MW}$.

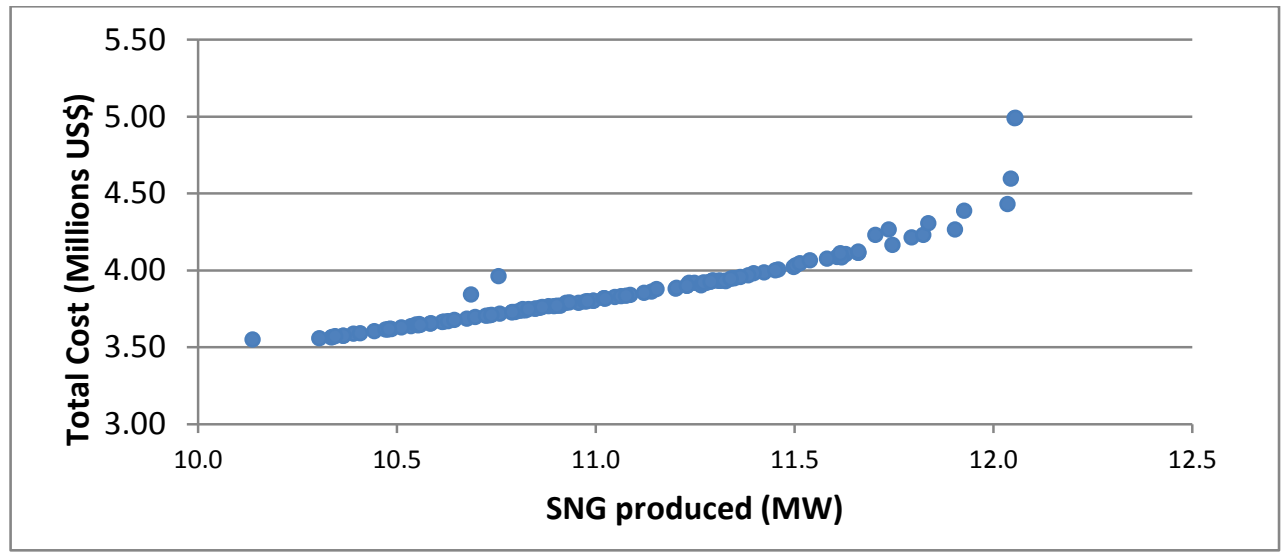

Figure 2. Results of the optimization for $20 \mathrm{MW}_{\text {daf biomass }}$ input in the gasifier

This preliminary analysis of the microalgae-to-SNG conversion system shows that increasing the gasification pressure, more SNG can be produced with the same input of biomass. Considering the set of optimal solutions presented in the Pareto Front (Figure 2 ) the energy efficiency of the system is between and 49 and $57 \%$ with a average value of $52 \%$. These results are between 2 to $10 \%$ lower of those obtained by Gassner et al. (2011) using wood as feedstock to produce SNG with the same configuration of hydrothermal gasification and separation system. This can be explained by the fact that the system presented in this paper includes the electric power for the biomass production (microalgae cultivation and dewatering) which is not included in the analysis with wood. These steps are energy intensive and must be optimized considering alternative photobioreactor designs that can be able to reduce the energy input per unit of biomass produced. Seasonal variations in the solar radiation incidence and other 
parameters like the temperature of cultivation and the nutrients and $\mathrm{CO}_{2}$ supply may be analyzed as well in more detailed models, in order to estimate the optimal configuration of the whole system with minimum cost and maximum efficiency.

\section{References}

A.P.Carvalho, L.A.Meireles, X.Malcata, 2006, Microalgal reactors: a review of enclosed system designs and performances. Biotechnol Prog. v.22 (6), pp.1490-506.

B.Ketheesan, N. Nirmalakhandan, 2012, Feasibility of microalgal cultivation in a pilot-scale airlift-driven raceway reactor, Bioresource Technology v.108, pp. 196-202.

C.Posten, G. Schaub, 2009, Microalgae and terrestrial biomass as source for biofuels - aprocess view. Journal of biotechnology, v.142, ${ }^{\circ} 1$, pp.64-69.

J.B.K.Park, R.J. Craggs, A.N. Shilton, 2011, Wastewater treatment high rate algal ponds for biofuel production, Bioresource Technology v.102, pp.35-42.

J.C.Weissman, R.P.Goebel, 1987, Design and Analysis of Microalgal Open Pond Systems for the Purpose of Producing Fuels, Report of U.S. Department of Energy, 214p.

J.R.Benemann, 2008, Opportunities and challenges in algae biofuels production, Position Paper, Algae World 2008.

J.S.Boyer. , 1982, Plant productive and environment (crop genetic improvement) Scicence v. 218 $\mathrm{n}^{\circ} 4571$, pp. 443-448.

K.Annamalai, J.M.Sweeten, S.C.Ramalingam, 1987, Estimation of gross heating values of biomass fuels, v.30 (4), pp. 1205-1208.

L.Brennan, P. Owende, 2010, Biofuels from microalgae-A review of technologies for production, processing, and extraction of biofuels and co-products. Renewable and Sustainable Energy Reviews v.14, pp.557-577.

L.Gerber, M. Gassner, F. Marechal, 2011, Systematic integration of LCA in process system design: Application to combined fuel and electricity production from lignocellulosic biomass, Computers and Chemical Engineering v.35, pp. 1265-1280.

M.Gassner, F. Vogel, G. Heyen, F. Marechal, 2011, Optimal process design for the polygeneration of SNG, power and heat by hydrothermal gasification of waste biomass: Thermo-economic process modelling and integration, Energy \& Environmental Science, v.4, pp. 1726-1741

M.R.Tridici, 2010, Photobiology of microalgae mass cultures: understanding the tools for the next green revolution, Biofuels v. 1(1), pp. 143-162.

N-H.Norsker, M.J. Barbosa, M.H. Vermuë, R.H.Wijffels, 2011, Microalgal production - a close look at the economics, Biotechnology Advances, v.29, pp.24-27.

P.J.B.Williams, L.M.L. Laurens, 2010, Microalgae as biodiesel \& biomass feedstocks: Review \& analysis of the biochemistry, energetics \& economics. Energy \& Environmental Science, v.3, pp. 554-590.

P.K.Campbell, T.Beer, D.Batten, 2011. Life cycle assessment of biodiesel production from microalgae in ponds. Bioresour.Technol. v.102, pp.50-56.

P. Schlagermann , G.Göttlicher, D. Dillschneider, R. Rosello-Sastre, C. Posten, 2012, Composition of Algal Oil and Its Potential as Biofuel. Journal of Combustion, vol. 2012, Article ID 285185, 14pp.

R.Putt, M. Singh, S. Chinnasamy, K.C. Das, 2011, An efficient system for carbination of highrate algae pond water to enhance $\mathrm{CO}_{2}$ mass transfer. Bioresource Technology 102 , pp. 32403245 . 